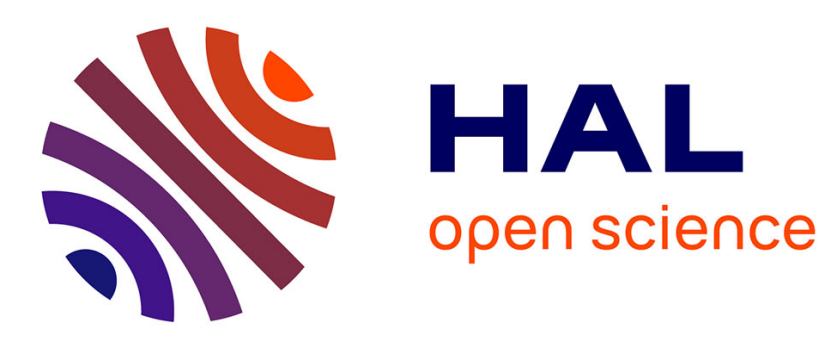

\title{
Impact of sodium hypochlorite on rejection of non-steroidal anti-inflammatory drugs by biomimetic forward osmosis membranes
}

Walid Ghamri, Patrick Loulergue, Irena Petrinic, Claus Helix-Nielsen, Maxime Pontie, Noureddine Nasrallah, Kamel Daoud, Anthony Szymczyk

\section{To cite this version:}

Walid Ghamri, Patrick Loulergue, Irena Petrinic, Claus Helix-Nielsen, Maxime Pontie, et al.. Impact of sodium hypochlorite on rejection of non-steroidal anti-inflammatory drugs by biomimetic forward osmosis membranes. Journal of Membrane Science, 2021, 633, pp.119388. 10.1016/j.memsci.2021.119388 . hal-03268392

\section{HAL Id: hal-03268392 \\ https://hal.science/hal-03268392}

Submitted on 1 Jul 2021

HAL is a multi-disciplinary open access archive for the deposit and dissemination of scientific research documents, whether they are published or not. The documents may come from teaching and research institutions in France or abroad, or from public or private research centers.
L'archive ouverte pluridisciplinaire HAL, est destinée au dépôt et à la diffusion de documents scientifiques de niveau recherche, publiés ou non, émanant des établissements d'enseignement et de recherche français ou étrangers, des laboratoires publics ou privés. 


\title{
Impact of sodium hypochlorite on rejection of non-steroidal anti- inflammatory drugs by biomimetic forward osmosis membranes
}

\author{
Walid Ghamri $^{1,2}$, Patrick Loulergue ${ }^{1}$, Irena Petrinić ${ }^{3}$, Claus Hélix-Nielsen ${ }^{3,4}$, Maxime Pontié ${ }^{5}$, \\ Noureddine Nasrallah ${ }^{2}$, Kamel Daoud ${ }^{2}$, Anthony Szymczyk ${ }^{1 *}$ \\ ${ }^{1}$ Univ Rennes, CNRS, ISCR - UMR 6226, F-35000 Rennes, France \\ ${ }^{2}$ University of Science and Technology Houari Boumediene, Department of Mechanical and \\ Process Engineering, Algiers, Algeria \\ ${ }^{3}$ University of Maribor, Faculty of Chemistry and Chemical Engineering, Smetanova 17, \\ 2000 Maribor, Slovenia \\ ${ }^{4}$ Department of Environmental Engineering, Technical University of Denmark, \\ Bygningstorvet 115, 2800, Kongens, Lyngby, Denmark \\ ${ }^{5}$ Angers University, Department of Chemistry, 2 Bd. Lavoisier, F-49045 Angers 01, France
}

*Corresponding author: anthony.szymczyk@univ-rennes1.fr

\begin{abstract}
Biomimetic forward osmosis membranes with a polyamide-based active layer containing polymersomes incorporating aquaporins were exposed to various free chlorine doses (free chlorine concentration $\mathrm{x}$ exposure time) and $\mathrm{pH}$. Membrane chlorination was found to decrease the apolar/polar balance of the membrane surface energy and to increase its negative surface charge density. A substantial modification of the hydrogen-bond network in the membrane active layer was also highlighted. The separation performance of biomimetic membranes was also impacted by chlorine-induced chemical ageing. For the lowest free chlorine doses (100 ppm.h), the reverse salt flux was found to increase with respect to the pristine membrane while the water flux dropped by 10-20\%. For higher free chlorine doses (1000 and 10000 ppm.h), both the reverse salt flux and the water flux were found higher than for the pristine membrane. These behaviors were explained by the combination of several mechanisms with possible antagonist effects, namely a reduced internal concentration polarization due to ageing of the membrane support material, and modifications of the
\end{abstract}


hydrogen-bond network and surface charge density of the membrane active layer. Although the degradation caused by sodium hypochlorite increased the draw-solute loss per unit of water passed, the biomimetic membranes maintained their rejection ability towards naproxen and diclofenac as rejections higher than $95.9 \%$ were measured irrespective of the ageing conditions.

Keywords: Biomimetic membranes, Forward osmosis, Sodium hypochlorite, Ageing, Pharmaceutical compounds 


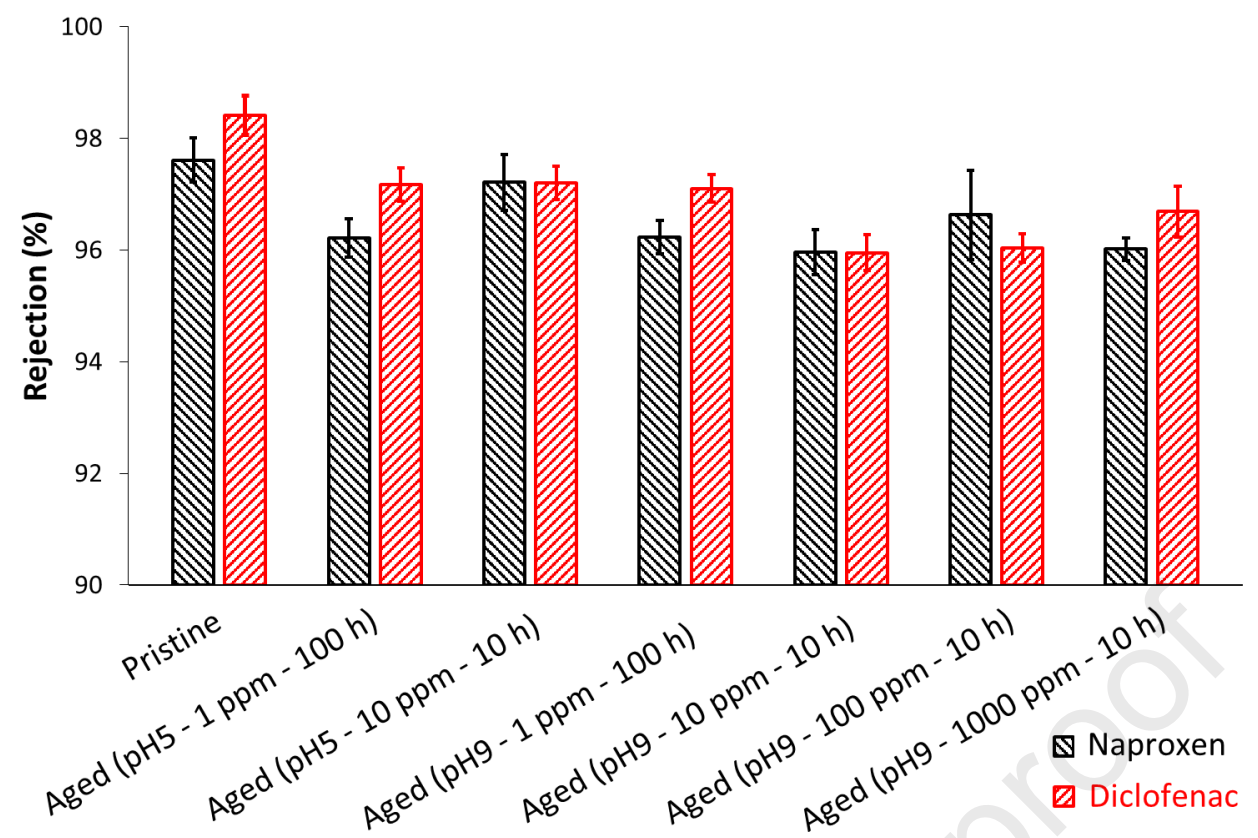




\section{Authors statements}

W. Ghamri: Investigation, Formal analysis, Writing - Original Draft

P. Loulergue: Conceptualization, Formal analysis, Supervision, Writing - Review \& Editing Irena Petrinić: Conceptualization, Supervision, Writing - Review \& Editing Claus Hélix-Nielsen: Conceptualization, Writing - Review \& Editing

Maxime Pontié: Investigation, Writing - Review \& Editing

N. Nasrallah: Funding acquisition

K. Daoud: Supervision, Writing - Review \& Editing, Funding acquisition

A. Szymczyk: Conceptualization, Formal analysis, Supervision, Writing - Review \& Editing, Funding acquisition 


\section{Introduction}

Freshwater is essential to human life and the functioning of any terrestrial ecosystem. However, the world's drinking water resource is becoming increasingly scarce as human activities release increasing amounts of organic and mineral pollutants that are not properly disposed of.

Membrane separation processes are already recognized worldwide as promising tools for solving some of the major problems of our modern societies in a process intensification strategy [1]. Forward osmosis (FO) is an emerging membrane process based on natural osmosis, i.e. the spontaneous diffusion of water through a semipermeable membrane $[2,3]$. Water diffusion occurs from a dilute feed solution to a concentrated draw solution (with a higher osmotic pressure than the feed solution) [4]. FO has gained attention in recent years as a promising process capable of (i) handling heavily impaired water sources and (ii) concentrating solutions with a high fouling potential as it does not use any transmembrane hydraulic pressure difference [5]. It has been proved efficient for liquid food concentration [6,7], wastewater reclamation [8,9], trace organic compounds removal [10-14], etc.

Currently, commercially available FO membranes are cellulose triacetate (CTA) membranes, polyamide (PA) thin-film composite membranes and biomimetic membranes with aquaporin (AQP) proteins incorporated into a PA-based selective layer [15-18]. AQPs facilitate water diffusion while being extremely selective by preventing the passage of almost all other species [19-21]. The application of AQP-based membranes has shown promising results in various applications [3,22].

Despite the growing interest in the FO process, there are very few studies devoted to the effect of chemical cleaning or exposure of FO membranes to residual oxidizing agents (e.g. incomplete dechlorination that might occasionally occur in water and wastewater treatment) on their physicochemical properties and separation performance. Nguyen et al. studied the change in performance (water flux and reverse salt flux) and properties of asymmetric CTA and thin-film composite PA membranes resulting from exposure to chlorine under acidic and alkaline conditions [16]. They found that the chlorination of PA-based membranes was greater than that of CTA-based membranes. Li et al investigated the impact of various cleaning agents (hydrochloric acid, sodium hypochlorite, disodium ethylenediaminetetraacetic acid, sodium dodecyl sulfate and Alconox) on the performance of a biomimetic membrane 
with AQP-liposomes incorporated into a PA active layer [21]. They observed an increase in the water flux along with a rather stable rejection of the salt contained in the draw solution after chemical cleaning and concluded that proper chemical cleaning of AQP membranes might be beneficial before use. It should be noted, however, that only a few works reported on the impact of chemical cleaning on the rejection of target solutes contained in the feed solution [23].

The aim of this work was to assess the chemical resistance of a new class of FO biomimetic membranes with AQP-polymersomes into a PA-based active layer [24]. The main advantages of polymersomes over liposomes are their better physical and chemical stability as well as the possibility of introducing functional groups for covalent bonding to the PA active layer [24]. AQP membranes were exposed to sodium hypochlorite solutions of various concentrations (1$1000 \mathrm{ppm})$, under acidic ( $\mathrm{pH}$ 5) and alkaline ( $\mathrm{pH}$ 9) conditions, and for different times (10 and $100 \mathrm{~h}$ ). A thorough membrane characterization was carried out in order to gain insight into the impact of chemical cleaning on their surface properties. Modifications of the latter were then correlated with variations of membrane separation performance, focusing on the water flux, the reverse salt flux but also on the rejection of non-steroidal anti-inflammatory drugs (diclofenac and naproxen).

\section{Materials and methods}

\subsection{Membranes}

Flat-sheet biomimetic membranes were provided by Aquaporin A/S (Kgs. Lyngby, Denmark). These were thin-film composite membranes with a polyethersulfone (PES) porous support material covered by a PA active layer incorporating AQP-polymersomes [25]. The experimental protocol for the development of these AQP membranes was described by Górecki et al. [24]. Briefly, polymersomes incorporating Aquaporin Z proteins are prepared from a mixture of diblock and triblock amphiphilic copolymers, poly(2-methyl-2-oxazoline)block-poly(dimethylsiloxane) (PMOXA-PDMS) and poly(2-methyl-2-oxazoline)-blockpoly(dimethylsiloxane)-block-poly(2-methyl-2-oxazoline) (PMOXA-PDMS-PMOXA) with the addition of amine terminated PDMS. AQP-polymersomes are further incorporated into the 
membrane via the active layer synthesis based on interfacial polymerization reaction between m-phenylenediamine (MPD), $\varepsilon$-Caprolactam and trimesoyl chloride (TMC).

According to Górecki et al., the addition of the amino-modified PDMS during reconstitution of the AQP-polymersomes allows for covalent bonding of the vesicles to the PA chains [24].

\subsection{Membrane ageing}

Static ageing experiments were performed by soaking the AQP membranes in sodium hypochlorite $(\mathrm{NaOCl})$ solutions of various total free chlorine concentrations (from 1 to 1000 ppm) at two different $\mathrm{pH}$ (5 and 9) for exposure times ranging from 10 to 100 hours. Hypochlorite solutions used for ageing experiments were prepared from dilution of a commercial bleach solution (La Croix, $\mathrm{Fr}-96000$ ppm NaOCl). Their $\mathrm{pH}$ was adjusted with $0.1 \mathrm{~mol} \mathrm{~L}^{-1} \mathrm{HCl}$ and $\mathrm{NaOH}$ solutions of analytical grade. Ageing experiments were performed at room temperature $\left(22 \pm 1{ }^{\circ} \mathrm{C}\right)$. Membrane samples were further rinsed thoroughly with deionized (DI) water to remove any traces of bleach solution or possible polymer degradation products and were further stored in DI water at $4^{\circ} \mathrm{C}$ prior to use.

\subsection{Membrane characterization}

\subsubsection{Zeta Potential}

A SurPass 3 electrokinetic analyzer (Anton Paar Gmbh, Graz, Austria), equipped with $\mathrm{Ag} / \mathrm{AgCl}$ electrodes and an adjustable-gap cell, was used to measure tangential streaming current. Tangential measurements avoid some issues that may be encountered with transversal measurements when applied to composite membranes with ionic retention properties [26,27]. The streaming current technique was preferred over the streaming potential to avoid any potential contribution of the electrical conduction through the membrane support material $[28,29]$. The distance between the membrane samples was set to $100 \pm 5 \mu \mathrm{m}$. All electrokinetic measurements were conducted at room temperature with $0.001 \mathrm{~mol} \mathrm{~L}^{-1} \mathrm{KCl}$ background solutions in the $\mathrm{pH}$ range 3-9 (the $\mathrm{pH}$ was adjusted with $0.1 \mathrm{~mol} \mathrm{~L}^{-1} \mathrm{HCl}$ and $\mathrm{KOH}$ solutions). All measurements were duplicated. The membrane zeta potential $(\zeta)$ was determined from the streaming current $\left(I_{s}\right)$ measurements by means of the equation: 


$$
I_{s}=\frac{W h_{c h} \varepsilon_{0} \varepsilon_{r} \Delta P}{\eta L} \zeta
$$

where $L$ and $W$ are the length and the width of the membrane samples, respectively, $h_{c h}$ is the distance between the two membrane samples in the adjustable-gap cell, $\Delta P$ is the pressure difference, $\varepsilon_{0}$ is the vacuum permittivity, $\varepsilon_{r}$ is the dielectric constant of the background solution and $\eta$ its dynamic viscosity.

\subsubsection{FTIR-ATR}

FTIR-ATR spectroscopy was carried out with a Spectrum 100 Fourier Transform Infrared Spectrometer (Perkin Elmer) equipped with a single-reflection diamond crystal ATR element. Each spectrum was obtained from 20 scans.

\subsubsection{Contact angle}

A GBX-DS apparatus was used to measure contact angles (sessile drop method). At least 10 equilibrium contact angles were determined for each membrane. The apolar $\left(\gamma_{S}^{L W}\right)$, electron acceptor $\left(\gamma_{S}^{+}\right)$and electron donor $\left(\gamma_{S}^{-}\right)$components of the surface tension of new and aged AQP membranes were determined from the Good - Van Oss theory [30]:

$\gamma_{L}\left(1+\cos \theta_{L}\right)=2\left(\sqrt{\gamma_{L}^{L W} \gamma_{S}^{L W}}+\sqrt{\gamma_{L}^{+} \gamma_{S}^{-}}+\sqrt{\gamma_{L}^{-} \gamma_{S}^{+}}\right)$

where $\gamma_{L}$ is the surface tension of the liquid $L, \theta_{L}$ is the contact angle measured with this liquid, $\gamma_{L}^{L W}, \gamma_{L}^{+}$and $\gamma_{L}^{-}$are the apolar (Lifshitz - van der Waals), electron acceptor and electron donor components of the liquid surface tension, respectively.

The three components of the membrane surface tension $\left(\gamma_{S}^{L W}, \gamma_{S}^{+}\right.$and $\left.\gamma_{S}^{-}\right)$were then determined from contact angles measured with three liquids (DI water, formamide and diiodomethane) by solving the system of equations obtained by writing Eq. (2) for each liquid. The different components of the liquid surface tension are given in Table 1 . 


\begin{tabular}{|c|c|c|c|c|}
\cline { 2 - 5 } \multicolumn{1}{c|}{} & $\gamma_{L}\left(\mathrm{~mJ} . \mathrm{m}^{-2}\right)$ & $\gamma_{L}^{L W}\left(\mathrm{~mJ} . \mathrm{m}^{-2}\right)$ & $\gamma_{L}^{+}\left(\mathrm{mJ}^{\mathrm{c}} \mathrm{m}^{-2}\right)$ & $\gamma_{L}^{-}\left(\mathrm{mJ} . \mathrm{m}^{-2}\right)$ \\
\hline Water & 72.8 & 21.8 & 25.5 & 25.5 \\
\hline Formamide & 58.0 & 39.0 & 2.28 & 39.6 \\
\hline Diiodomethane & 50.8 & 50.8 & 0 & 0 \\
\hline
\end{tabular}

Table 1. Surface tension components for water, formamide and diiodomethane.

\subsubsection{X-ray photoelectron spectroscopy $(X P S)$}

XPS analyses were performed with a Kratos Analytical spectrometer (Shimadzu) with the monochromatic $\mathrm{Al} \mathrm{K} \alpha$ radiation as an $\mathrm{X}$-ray excitation source $(1486 \mathrm{eV})$. The membrane samples were kept overnight under a high vacuum prior to measurements. The XPS data were post-processed using the CasaXPS software.

\subsubsection{Scanning electron microscopy (SEM)}

A JEOL JDM 7100F high-resolution field-emission scanning electron microscope was used to investigate membrane morphology. Samples were coated with an Au/Pd alloy before analysis.

\subsubsection{Atomic force microscopy (AFM)}

AFM analyses were performed with a Nanoscope III atomic force microscopy set-up (Bruker, France). The membrane samples were imaged in contact mode in air with a scan rate of $1 \mathrm{~Hz}$ and $400 \times 400$-pixel resolution, using cantilevers with a spring constant of $0.2 \mathrm{~N} \cdot \mathrm{m}^{-1}$ and a resonant frequency of $13 \mathrm{kHz}$. The scanning area was $10 \mu \mathrm{m} \times 10 \mu \mathrm{m}$. The image analysis was carried out with the SPMLab602 software from Brucker (France).

\subsection{Membrane performance in FO experiments}

The laboratory scale experimental setup used to carry out FO experiments is described in Fig. 1. The membrane sample $\left(3 \times 2 \mathrm{~cm}^{2}\right)$ was hosted in a cross-flow cell. Two peristaltic pumps were used to circulate the feed and draw solutions (counter-current; flow rate: $12.5 \mathrm{~mL} \cdot \mathrm{min}^{-1}$ ). 
Experiments were performed in a batch configuration with $250 \mathrm{~mL}$ (initial volumes) of feed and draw solutions. An electronic scale and a conductivity meter were used to monitor the mass and conductivity of the feed solution.

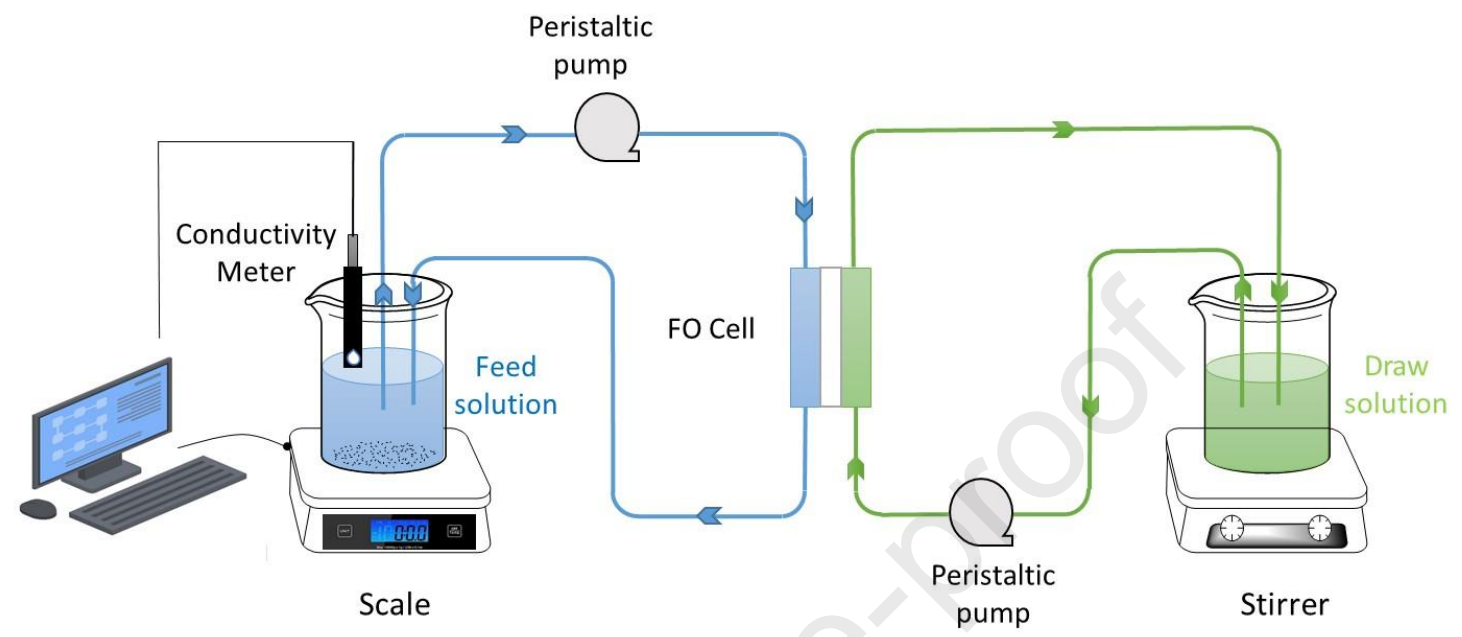

Figure 1. Experimental FO setup.

Each membrane was first conditioned for one hour using DI water as the feed solution and a $1 \mathrm{M} \mathrm{NaCl}$ draw solution (baseline step). Next, the FO experiment was performed for 3 hours using a feed solution containing a mixture of naproxen and diclofenac (Table 2), with 10 $\mathrm{mg} / \mathrm{L}$ of each pharmaceutical compound, and a $1 \mathrm{M} \mathrm{NaCl}$ draw solution. The $\mathrm{pH}$ was $5.6 \pm$ 0.2 in both compartments. All experiments were carried out at room temperature $\left(22 \pm 1{ }^{\circ} \mathrm{C}\right)$ and duplicated.

\begin{tabular}{|c|c|c|}
\hline & Naproxen & Diclofenac \\
\hline Molecular formula & $\mathrm{C}_{14} \mathrm{H}_{14} \mathrm{O}_{3}$ & $\mathrm{C}_{14} \mathrm{H}_{11} \mathrm{Cl}_{2} \mathrm{NO}_{2}$ \\
\hline Molar mass $\left(\mathrm{g} \cdot \mathrm{mol}^{-1}\right)$ & 230.26 & 296.15 \\
\hline$\overline{p K_{a}}$ & 4.15 & 4.15 \\
\hline
\end{tabular}

Table 2. Pharmaceuticals compounds used to assess the impact of ageing on the FO performance of AQP membranes.

The water flux $\left(J_{w}\right)$ through the membrane was calculated as: 


$$
J_{w}=\frac{\Delta m_{f s}}{\Delta t A \rho_{f s}}
$$

where $m_{f s}$ and $\rho_{f s}$ are the mass and the density of the feed solution, respectively, $t$ is the time and $A$ is the membrane surface area.

The reverse salt flux $\left(J_{s}\right)$ was determined by monitoring the increase in $\mathrm{NaCl}$ concentration in the feed solution as a function of time and Eq. (4):

$$
J_{s}=\frac{\Delta\left(C_{f s, N a C l} V_{f s}\right)}{A \Delta t}
$$

where $C_{f s, N a C l}$ is the sodium chloride concentration in the feed solution (determined from conductivity measurements) and $V_{f s}$ is the feed solution volume.

Finally, the rejection of a pharmaceutical compound $i\left(R_{i}\right)$ was calculated as suggested by Kedwell et al. in order to account for that in batch FO experiments the draw solution continuously dilutes the solutes transported from the feed solution [31]:

$$
R_{i}=\left(1-\frac{j_{i}}{J_{W} C_{f s, i}}\right) \times 100
$$

with $C_{f s, i}$ the concentration of the pharmaceutical solute $i$ (naproxen or diclofenac) in the feed solution and $j_{i}$ its molar flux that was determined using the following equation [31]:

$$
j_{i}=\frac{\Delta C_{f s, i} V_{f s}}{A \Delta t}
$$

Equations (5) and (6) allow computing a rejection coefficient that is independent of the dilution effect of the draw solution.

The concentrations of naproxen and diclofenac (samples were collected every $30 \mathrm{~min}$ ) were determined by HPLC (Waters W2690/5) equipped with a UV detector (fixed wavelength: 230 $\mathrm{nm}$ for naproxen and $277 \mathrm{~nm}$ for diclofenac). Analyses were performed at $20 \pm 1^{\circ} \mathrm{C}$ with a 3.5 $\mu \mathrm{m}, 50 \times 4.6 \mathrm{~mm}$ XBridge ${ }^{\circledR}$ C18 column (Milford, USA) and a mixture of water and 
acetonitrile with $0.1 \%(\mathrm{v} / \mathrm{v})$ formic acid (HPLC grade, VWR, USA) as eluent (gradient mode; 0-10 min: 40\% acetonitrile, 10-12 $\min : 60 \%$ acetonitrile, $12-14 \mathrm{~min}$ : 40\% acetonitrile).

\section{Results and discussion}

\subsection{Surface characterization}

Fig. 2 shows the $\mathrm{pH}$ dependence of the zeta potential for the AQP membranes active layers before and after exposure to sodium hypochlorite at $\mathrm{pH} 5$ and 9. The pristine AQP membrane exhibited the usual electrokinetic features of PA-based membranes [32]. The isoelectric point was found close to $\mathrm{pH} 3$ and the membrane was then negatively charged over a wide range of $\mathrm{pH}$. The sharp decrease in the zeta potential in the $\mathrm{pH}$ range 3-5 followed by a gradual levelling off is typical of the ionization process of surfaces bearing functional groups with weak acid properties. PA-based membranes indeed bear carboxylic acid groups due to hydrolysis of unreacted TMC residues after the interfacial polymerization process [33,34]. A greater negative charge density was determined for membranes exposed to sodium hypochlorite, the impact on the membrane charge being more significant for membranes aged at $\mathrm{pH}$ 9. It is well-established that PA membranes with secondary amide groups undergo an $\mathrm{N}$-chlorination reaction (i.e. $-\mathrm{CON}(\mathrm{H})$ - is converted into $-\mathrm{CON}(\mathrm{Cl})$-) when brought into contact with sodium hypochlorite [35-37] (see Fig. S1 in the Supporting Information). However, the substitution of the amidic hydrogen by chlorine weakens the C-N bond, which makes chlorinated amides more prone to hydrolysis leading to the formation of carboxylic acids (see Fig. S1 in the Supporting Information). Hydrolysis of chlorinated amides being favored in an alkaline environment [37], the electrokinetic charge density of membranes exposed to sodium hypochlorite at $\mathrm{pH} 9$ is then expected to be more negative compared to that of membranes aged at $\mathrm{pH}$ 5. This argument is supported by the results shown in Fig. 2. It must be stressed, however, that additional physicochemical processes attributable to chlorine exposure also impact the membrane charge density, as it will be discussed hereafter. 


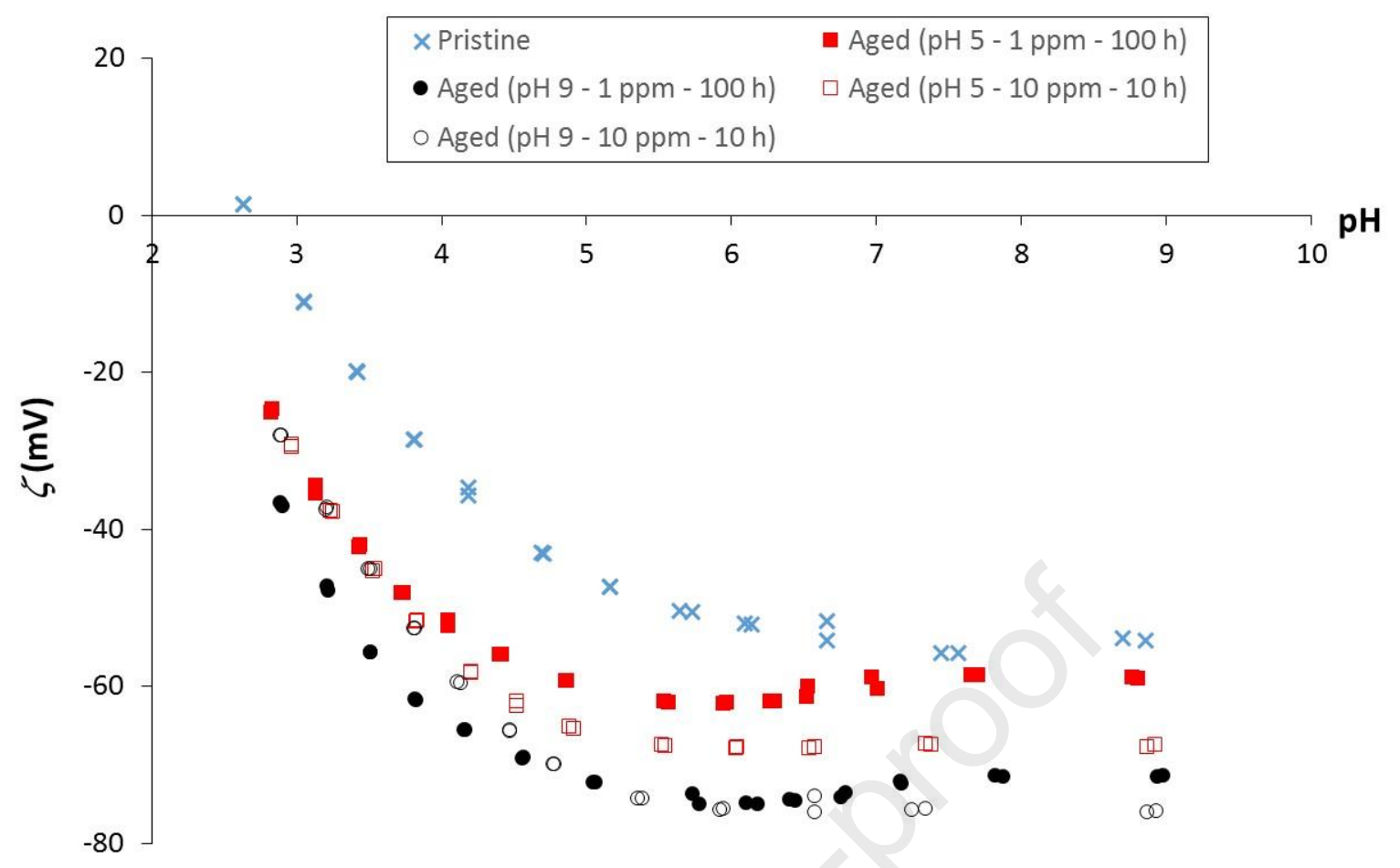

Figure 2. Zeta potential $(\zeta)$ of new and aged AQP membranes active layers vs. pH.

The apolar $\left(\gamma_{S}^{L W}\right)$, electron acceptor $\left(\gamma_{S}^{+}\right)$and electron donor $\left(\gamma_{S}^{-}\right)$components of the surface tension of new and aged AQP membranes are reported in Fig. 3 (the contact angles measured with water, formamide and diiodomethane are shown in Figure S2 of the Supporting Information). Unlike the apolar component, which was only weakly affected by exposure to sodium hypochlorite, both electron donor and electron acceptor components underwent substantial modifications. Overall, membrane chlorination was found to decrease the apolar / polar balance of the membrane surface energy $\left(\gamma_{S}^{L W} / \gamma_{S}^{A B}\right.$ with $\left.\gamma_{S}^{A B}=2 \sqrt{\gamma_{S}^{+} \gamma_{S}^{-}}\right)$, whatever the $\mathrm{pH}$ of the ageing solution. The electron donor component $\left(\gamma_{S}^{-}\right)$dramatically increased for all aged membranes, rising from $5.9 \mathrm{~mJ} . \mathrm{m}^{-2}$ for the new AQP membrane up to $39.5 \mathrm{~mJ} . \mathrm{m}^{-2}$ for the membrane aged in a $10 \mathrm{ppm} \mathrm{NaOCl}$ solution at $\mathrm{pH} 5$ for $10 \mathrm{~h}$. Overall, the increase in $\gamma_{S}^{-}$ was greater for membranes aged at $\mathrm{pH} 5$, which is the opposite of the trend observed for the evolution of zeta potentials (Fig. 2). It is important to note, however, that there is no contradiction between both techniques as the zeta potential of a surface is rarely directly related to the acid-base component of the surface energy [30]. Indeed, even though carboxylic acid groups contribute to $\gamma_{S}^{-}$, this latter derives from electron donor functionality present throughout the polymer structure [38]. The greater strengthening of the Lewis base character 
of membranes aged at $\mathrm{pH} 5$ most probably results from the binding of chlorine (which has lone electron pairs) since the $\mathrm{N}$-chlorination reaction is more favored at $\mathrm{pH} 5$ than at $\mathrm{pH} 9$ [37].

In contrast to $\gamma_{S}^{-}$, the electron acceptor component of the membrane surface tension $\left(\gamma_{S}^{+}\right)$ decreased with ageing, even though the variations of $\gamma_{S}^{+}$were much less than those of $\gamma_{S}^{-}$. The decrease in $\gamma_{S}^{+}$can be partly explained by the $\mathrm{N}$-chlorination process since amidic hydrogens contributing to $\gamma_{S}^{+}$are substituted by chlorine atoms (amidic hydrogens act as electron acceptors when involved in hydrogen bonds (HBs) with oxygen atoms of the neighboring PA chains and the block copolymers (PMOXA-PDMS and PMOXA-PDMS-PMOXA) that form the polymersomes incorporating the aquaporins).

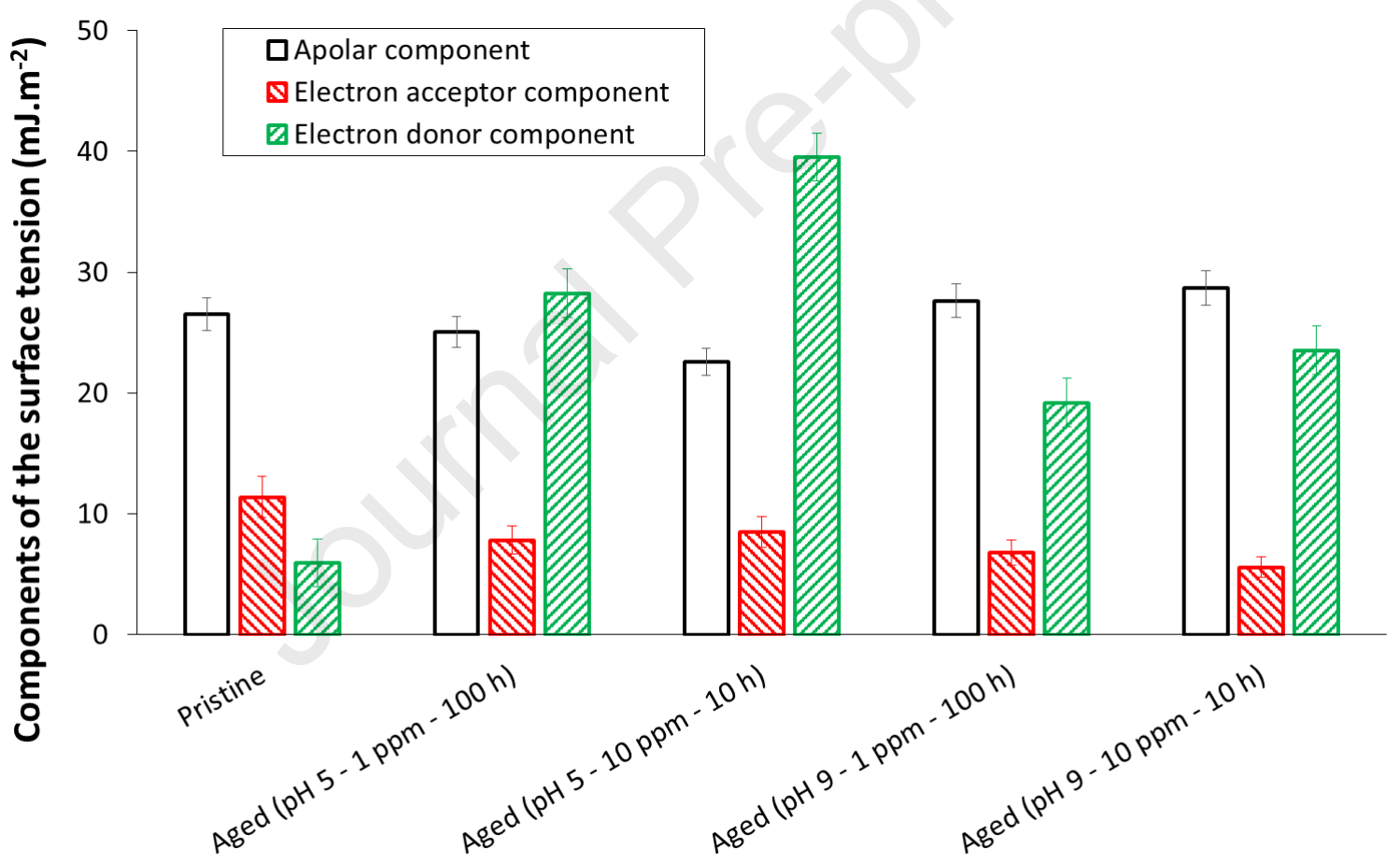

Figure 3. Apolar $\left(\gamma_{S}^{L W}\right)$, electron acceptor $\left(\gamma_{S}^{+}\right)$and electron donor $\left(\gamma_{S}^{-}\right)$components of the surface tension of new and aged AQP membranes.

The modification of the HB network in AQP membranes can be confirmed by FTIR- ATR spectroscopy. For instance, the amide I band (located around $1660 \mathrm{~cm}^{-1}$ [35]), corresponding mainly to the stretching of the carbonyl group $(\mathrm{C}=\mathrm{O})$ of the amide function, is expected to be shifted towards higher wavenumbers as a result of $\mathrm{N}$-chlorination [35]. It was not possible, 
however, to analyze the shift of the amide I band of the AQP membranes because it overlapped with a band from the membrane support material. Indeed, the penetration depth of the IR beam ( $\mu \mathrm{m}$ range) is more than the thickness of active layers obtained by interfacial polymerization (100 $\mathrm{nm}$ range), so the FTIR-ATR spectrum obtained by characterizing the active layer includes bands of both the active layer and the membrane support material [35]. This band detected around $1668 \mathrm{~cm}^{-1}$ (see Fig. 4) for the membrane support material does not belong to PES and therefore it indicates the presence of an additive. It was associated with the vibration of the $\mathrm{C}=\mathrm{O}$ bond of polyvinylpyrrolidone (PVP), which is a widely-used poreforming additive in the PES membranes synthesis $[39,40]$.

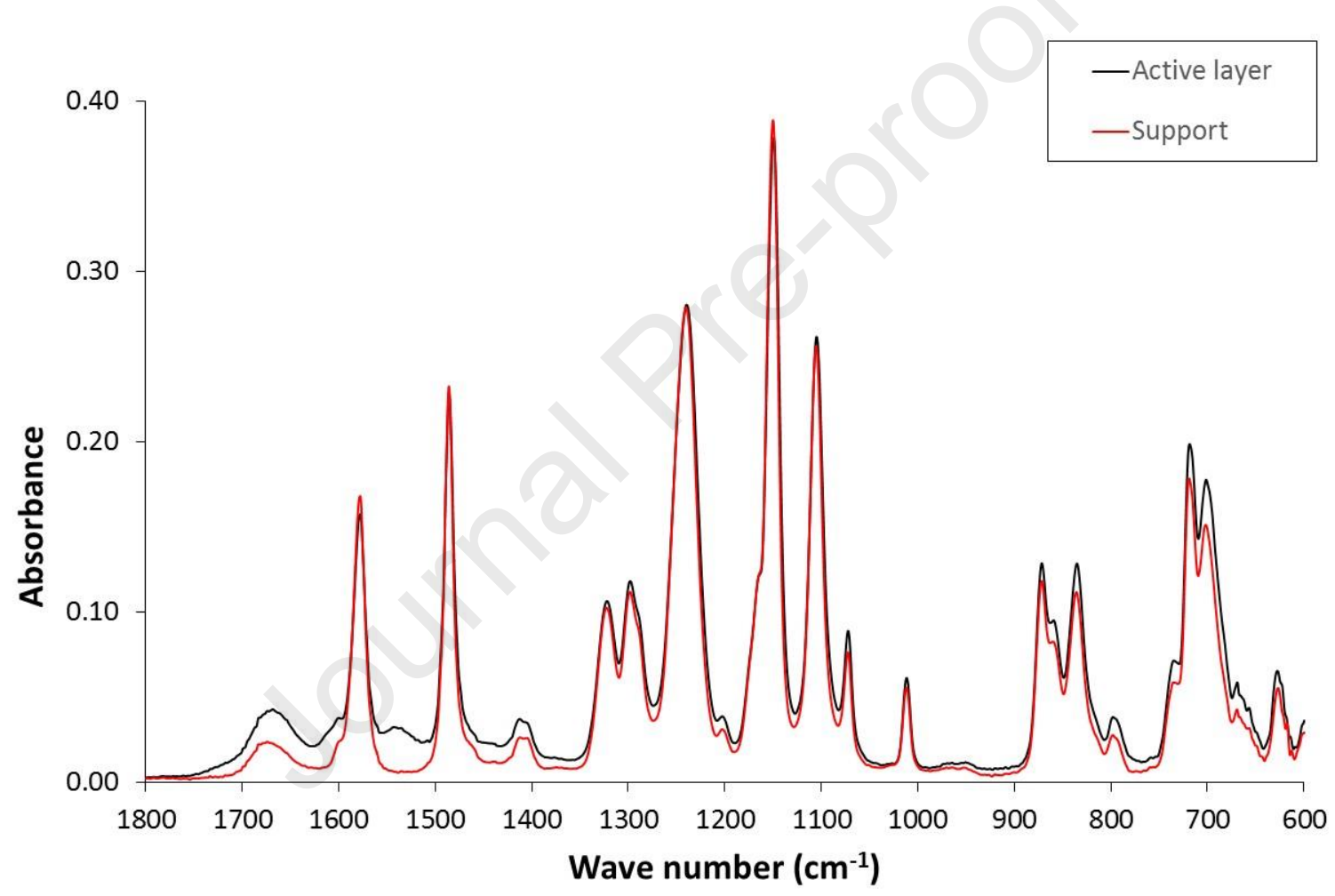

Figure 4. FTIR-ATR spectra of the pristine AQP membrane (support and active layer sides).

Fig. 4 shows the presence of the amide II band $\left(1543 \mathrm{~cm}^{-1}\right)$ on the active layer side without any overlap with bands originating from the membrane support material. The amide II band is mainly associated with bending of C-N-H [35] and is also impacted by the modification of the HB network. It was found to be shifted to lower wavenumbers (redshift) after exposure to sodium hypochlorite (see Fig. S3 in the Supporting Information). When the amidic hydrogen forms an $\mathrm{HB}$ bond with oxygen or nitrogen atom from a neighboring polymer chain, the bending vibration of $\mathrm{C}-\mathrm{N}-\mathrm{H}$ is restricted due to $\mathrm{HB}$. Let us consider two $\mathrm{N}$ atoms, referred to 
as $\mathrm{N}_{\mathrm{a}}$ and $\mathrm{N}_{\mathrm{b}}$. After chlorination of $\mathrm{N}_{\mathrm{a}}$, the HB bond Cl- $\mathrm{N}_{\mathrm{a}}-----\mathrm{H}-\mathrm{N}_{\mathrm{b}}$ is weakened due to the significant electronegativity of the chlorine atom, thus making the bending of $\mathrm{C}-\mathrm{N}_{\mathrm{b}}-\mathrm{H}$ easier and the associated band to shift to lower wavenumbers. The redshift of the amide II was found to be more important for membranes aged at $\mathrm{pH} 5$ (as mentioned above, the N-chlorination reaction is enhanced at $\mathrm{pH} 5$ [37]). For membranes aged at $\mathrm{pH} \mathrm{9,} \mathrm{the} \mathrm{amount} \mathrm{of} \mathrm{HBs} \mathrm{broken}$ by $\mathrm{N}$-chlorination was not high enough to produce a significant shift of the amide II band. Additional ageing experiments were carried out at $\mathrm{pH} 9$ under more severe conditions (100 and $1000 \mathrm{ppm}$ for $10 \mathrm{~h}$ ). They allowed highlighting the redshift of the amide II band, which reached $10 \mathrm{~cm}^{-1}$ for the AQP membrane exposed to the highest free chlorine dose (free chlorine concentration $x$ exposure time), i.e. 10000 ppm.h (see Fig. 5).

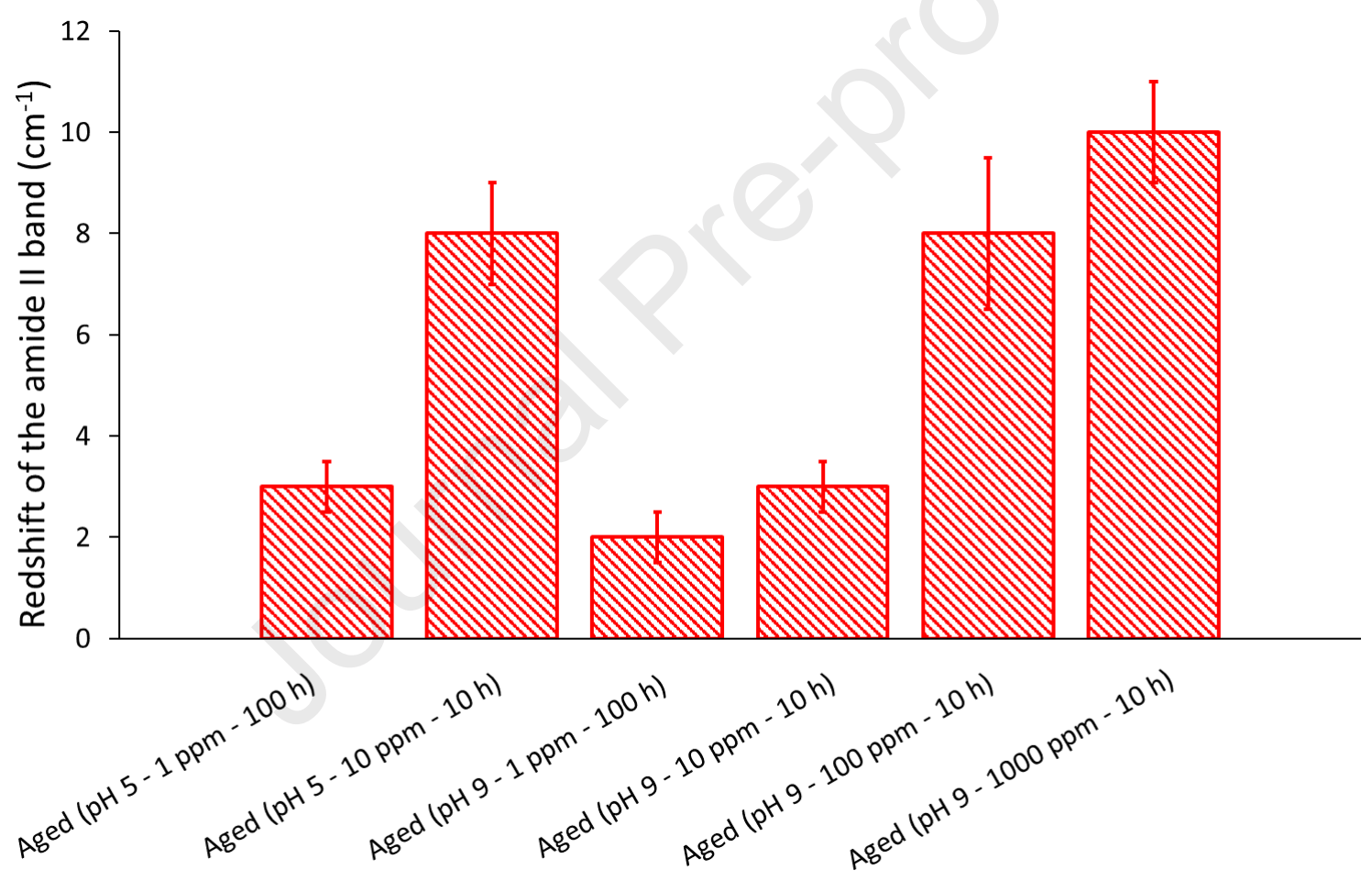

Figure 5. Redshift of the amide II band for aged AQP membranes.

A strong perturbation of the HB network within the membranes is also likely to impact the membrane charge density. This is illustrated in Fig. 6 which shows the zeta potential of AQP membranes active layers aged at $\mathrm{pH} 9$ for the various conditions shown in Fig. 5 (the zeta potential of the membrane before ageing is also displayed as reference ). Results reported in Fig. 6 were obtained at $\mathrm{pH} 5.6$ ( $\mathrm{pH}$ of the measuring solution: $1 \mathrm{mM} \mathrm{KCl}$ solution), i.e. the $\mathrm{pH}$ at which the FO experiments were performed (see section 2.4). The zeta potential was found 
to vary in a non-monotonous way with membrane ageing. For low sodium hypochlorite concentrations or free chlorine doses, the membranes were found to be significantly more negatively charged than the pristine membrane. It is worth noting that almost similar zeta potentials were obtained with membranes aged in both 1 and $10 \mathrm{ppm}$ sodium hypochlorite solutions. This might be because the time exposure was set inversely to the concentration for these two ageing experiments, so that the chlorine dose was identical for both ageing conditions (100 ppm.h).

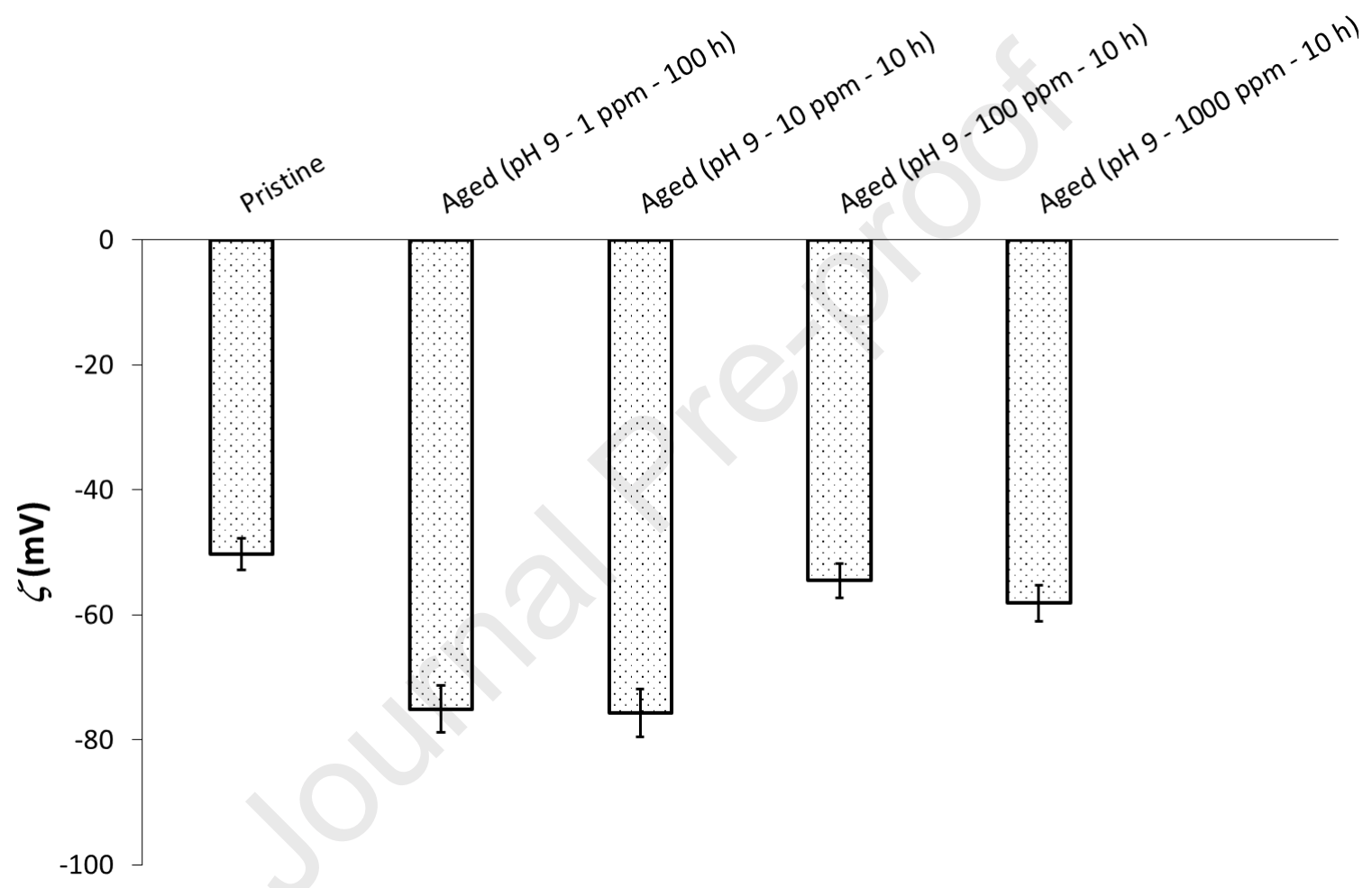

Figure 6. Zeta potential of the AQP membranes active layers (new and aged at $\mathrm{pH} 9$ ).

Measuring solution: $1 \mathrm{mM} \mathrm{KCl}, \mathrm{pH}=5.6$.

For harsher ageing conditions (100 and $1000 \mathrm{ppm}$ corresponding to free chlorine doses of 1000 and 10000 ppm.h, respectively), the AQP membranes were found to be less negatively charged, which can be explained by the impact of chlorination on the hydrogen bond network in the membrane active layer. As discussed above, chlorination of secondary amide groups suppresses some HBs between the PA chains. Among the different types of HBs within the membrane, those forming between the amidic hydrogen and the oxygen atom of the hydroxyl group of carboxylic acids (originating from either the hydrolysis of unreacted acyl chloride 
groups after the interfacial polymerization reaction or the hydrolysis of chlorinated amides after exposure to sodium hypochlorite) are likely to have a substantial impact on the membrane zeta potential. Indeed, this kind of $\mathrm{HBs}$ weakens the $\mathrm{OH}$ bond of carboxylic acid (see Fig. S4 in the Supporting Information). The latter therefore becomes stronger after Nchlorination, which makes it more difficult for the carboxylic acid group to be deprotonated. This mechanism therefore tends to make the charge density of the membrane less negative. The interplay of the breakage of these HBs and the hydrolysis of the amide functions explains the non-monotonous evolution of the zeta potential with the progression of membrane ageing by sodium hypochlorite.

\subsection{FO performance}

FO experiments were performed with a feed solution containing a mixture of naproxen and diclofenac $(10 \mathrm{mg} / \mathrm{L}$ of each organic) and a $1 \mathrm{M} \mathrm{NaCl}$ solution as a draw solution. The reverse salt flux $\left(J_{s \text { new }}\right)$ and the water flux $\left(J_{w \text { new }}\right)$ of the pristine membrane were found to be $3.5 \mathrm{~g} . \mathrm{m}^{-}$ ${ }^{2} \cdot \mathrm{h}^{-1}$ and $8.4 \mathrm{~L} \cdot \mathrm{m}^{-2} \cdot \mathrm{h}^{-1}$, respectively. The corresponding specific reverse solute flux $J_{s \text { new }} / J_{w}$ new (i.e. the amount of draw-solute loss per unit of water passed) was then equal to 0.4 g. $\mathrm{L}^{-1}$, which is similar to values reported in the literature for commercial AQP membranes with the same draw solution [17].

Fig. 7 shows the normalized reverse salt flux $\left(J_{s} / J_{s \text { new }}\right)$ and normalized water flux $\left(J_{w} / J_{w \text { new }}\right)$ for aged AQP membranes. Two distinct behaviors can be distinguished. For the lowest free chlorine doses (i.e. 100 ppm.h), the reverse salt flux increased with respect to the pristine membrane while the water flux dropped by $10-20 \%$. On the other hand, at higher free chlorine doses (1000 and $10000 \mathrm{ppm} . \mathrm{h}$ ), both $J_{s}$ and $J_{w}$ exceeded the reference values of the pristine membrane. 


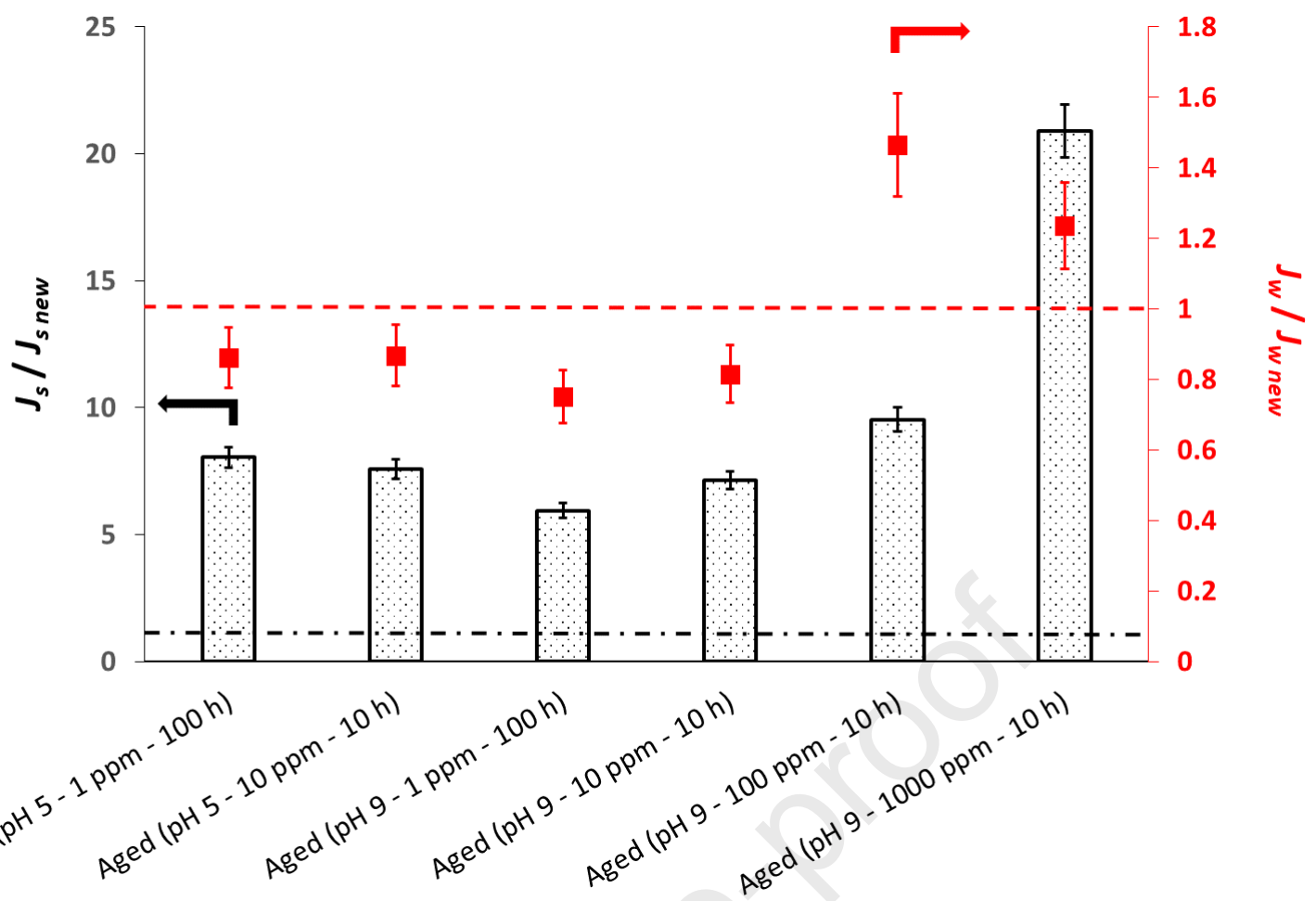

Figure 7. Normalized reverse salt flux $J_{s} / J_{s \text { new }}$ (left axis) and normalized water flux $J_{w} / J_{w n e w}$ (right axis) of aged AQP membranes. Horizontal lines show the performance of the pristine membrane.

The decrease in $J_{w}$ observed at relatively low free chlorine doses (100 ppm.h) might have several origins. First, one might think of aquaporin denaturation as a result of oxidation by sodium hypochlorite. While we cannot exclude this scenario, it should be pointed out that the drop of $J_{w}$ was in the range of $10-20 \%$ while it was shown, for similar membranes, that the incorporation of AQP-polymersomes in the PA layer was responsible for an increase of water permeability by more than $50 \%$ under reverse osmosis conditions [24]. It would also not explain the significant increase in $J_{s}$. It is worth noting that the block copolymers that form the polymersomes incorporating the aquaporins are covalently bonded to the PA backbone thanks to amine terminal groups [24] that can react with TMC monomers during the interfacial polymerization process. Furthermore, these polymersomes contain tertiary amide groups that cannot undergo $\mathrm{N}$-chlorination [41,42]. It was not possible to detect polymersomes directly in the membrane active layers by SEM (see Fig. S5 in the Supporting Information), presumably due to the low loading of the polymersomes. However, the presence of polymersomes was demonstrated by XPS since silicon, coming from the PMOXA-PDMS 
and PMOXA-PDMS-PMOXA blocks, was detected (see Figs. S6 and S7 in the Supporting Information). A similar amount of silicon was found for all the AQP membranes (atomic percentage: $0.24 \pm 0.04 \%$ ), thus confirming that the polymersomes incorporating aquaporins were not released from the membranes after exposure to sodium hypochlorite. Besides, it must be stressed that a decrease in $J_{w}$ along with an increase in $J_{s}$ was also reported after the exposure to sodium hypochlorite of a commercial PA-based FO membrane containing no aquaporins [16].

As discussed in Section 3.1, the N-chlorination process disrupts the HB network in the membrane. It can be envisaged that the breakage of a limited number of $\mathrm{HB}$ bonds could make the PA layer somewhat more compactable, which might lead to a decrease in $J_{w}$. It should be accompanied, however, by an increase in the resistance to salt transfer [16] contrary to what was observed in this work. AFM revealed morphological changes after exposure to sodium hypochlorite resulting in smoother active layers (see Table 3 as well as Fig. S8 in the Supporting Information). The decrease in membrane roughness after ageing is associated with a smaller effective surface area in contact with the feed solution, which contributes to the decrease in $J_{w}$.

\begin{tabular}{|c|c|c|c|c|c|c|c|}
\cline { 3 - 8 } & \multirow{2}{*}{} & \multirow{2}{*}{ Pristine } & \multicolumn{2}{|c|}{ Aged at pH 5 } & \multicolumn{4}{c|}{ Aged at pH 9 } \\
\cline { 3 - 8 } & & $\begin{array}{c}1 \mathrm{ppm} \\
-100 \mathrm{~h}\end{array}$ & $\begin{array}{c}10 \mathrm{ppm} \\
-10 \mathrm{~h}\end{array}$ & $\begin{array}{c}1 \mathrm{ppm} \\
-100 \mathrm{~h}\end{array}$ & $\begin{array}{c}10 \mathrm{ppm} \\
-10 \mathrm{~h}\end{array}$ & $\begin{array}{c}100 \mathrm{ppm} \\
-10 \mathrm{~h}\end{array}$ & $\begin{array}{c}1000 \mathrm{ppm} \\
-10 \mathrm{~h}\end{array}$ \\
\hline$R_{\text {avg }}(\mathrm{nm})$ & $100 \pm 4$ & $75 \pm 15$ & $75 \pm 13$ & $62 \pm 3$ & $65 \pm 15$ & $100 \pm 20$ & $84 \pm 8$ \\
\hline
\end{tabular}

Table 3. Average roughness $\left(R_{\text {avg }}\right)$ of the AQP membranes active layers before and after exposure to $\mathrm{NaOCl}$.

The substantial increase in the negative membrane charge density highlighted by electrokinetic measurement (Figs. 2 and 6) might also play a role in the decrease of $J_{w}$ as water molecule dynamics is decreased in charged (sub)nanometric pores compared to their uncharged counterparts as revealed by molecular dynamics simulations [43]. Still, it does not explain the increases in $J_{s}$ as salt rejection is expected to increase with the membrane charge density [27].

The membrane support material is also likely to be degraded by sodium hypochlorite. Notably, the PVP additive is highly sensitive to sodium hypochlorite $[39,40,44-47]$ and partly released from the membrane after degradation [47,48], leading to an increase of the 
membrane support material porosity. Fig. 8 shows the $\mathrm{pH}$ dependence of the zeta potential of the membrane support layers before and after exposure to sodium hypochlorite. More negative zeta potentials and a shift of the support-layer isoelectric point towards lower $\mathrm{pH}$ were observed. These results are in line with reported studies on chemical ageing of PES/PVP membranes by sodium hypochlorite [40,47] and confirm that the surface properties of the support layer of the AQP membranes were modified irrespective of the ageing conditions.

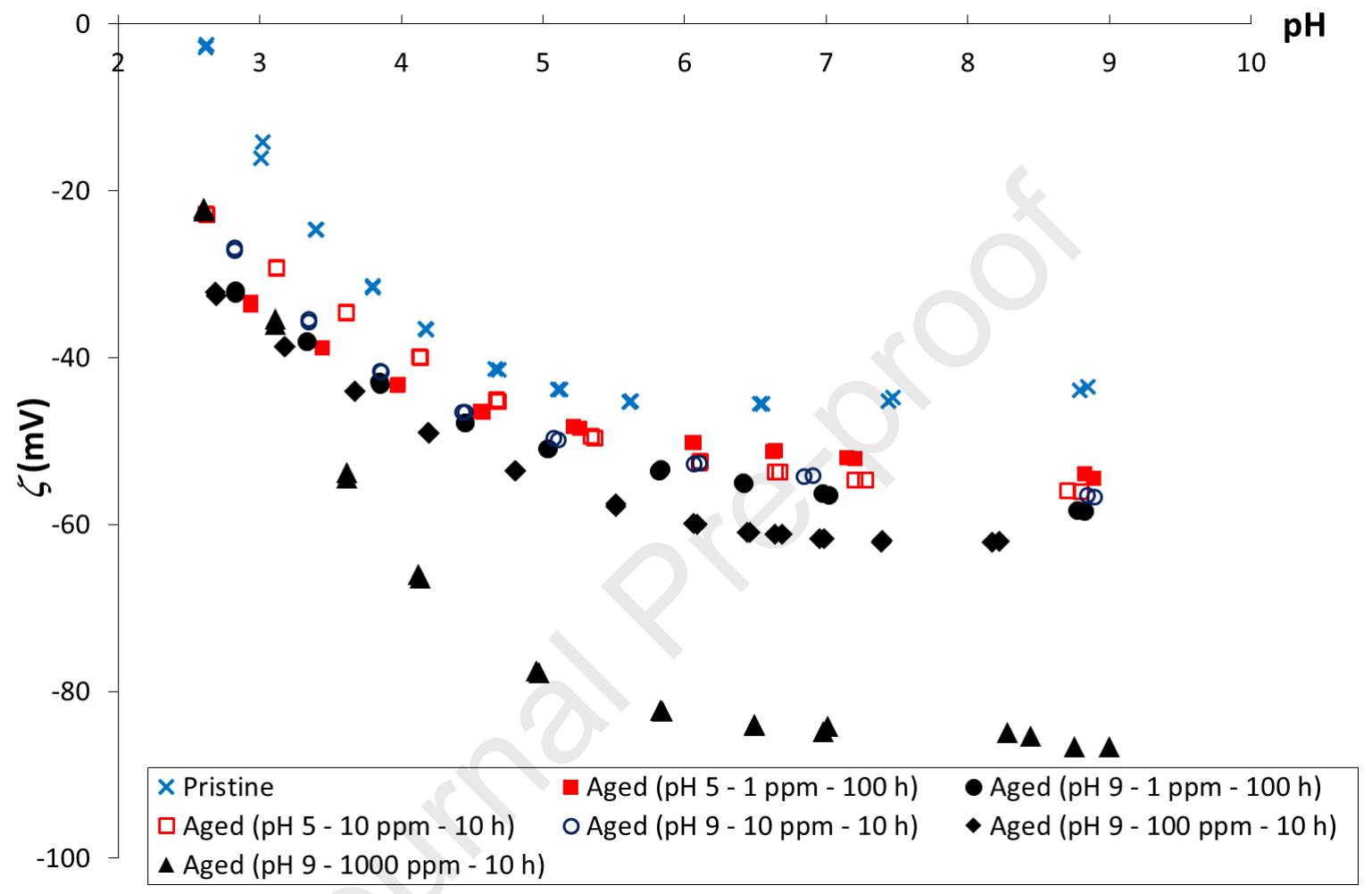

Figure 8. Zeta potential $(\zeta)$ of the membrane support before and after ageing vs. $\mathrm{pH}$.

The ratio of the infrared absorptions measured at $1668 \mathrm{~cm}^{-1}$ (characteristic band of the $\mathrm{C}=\mathrm{O}$ bond of PVP) and $1239 \mathrm{~cm}^{-1}$ (band associated with the ether bond of PES) for the PES/PVP supports of the different AQP membranes is shown in Fig. 9. The exposure to sodium hypochlorite resulted in a decrease of the relative amount of PVP in the membrane support. The partial release of PVP from the PES network therefore resulted in an increase in the effective porosity of the aged membrane supports [49]. In FO, the internal concentration polarization (ICP) occurring within the membrane support material acts as an unstirred layer to hinder solute diffusion [50]. Consequently, even a slight increase in the membrane support porosity is likely to reduce ICP (by reducing the resistance of the support to salt diffusion), which in turn increases the salt concentration difference through the membrane active layer, 
i.e. the driving force for salt diffusion towards the feed solution. However, even though the reduction of ICP within the membrane support could explain the rise of $J_{s}$, it would also increase the osmotic pressure difference through the membrane active layer and so the water flux. ICP itself thus cannot explain our findings at low free chlorine doses and most likely an interplay of the various mechanisms discussed above occurred during ageing.

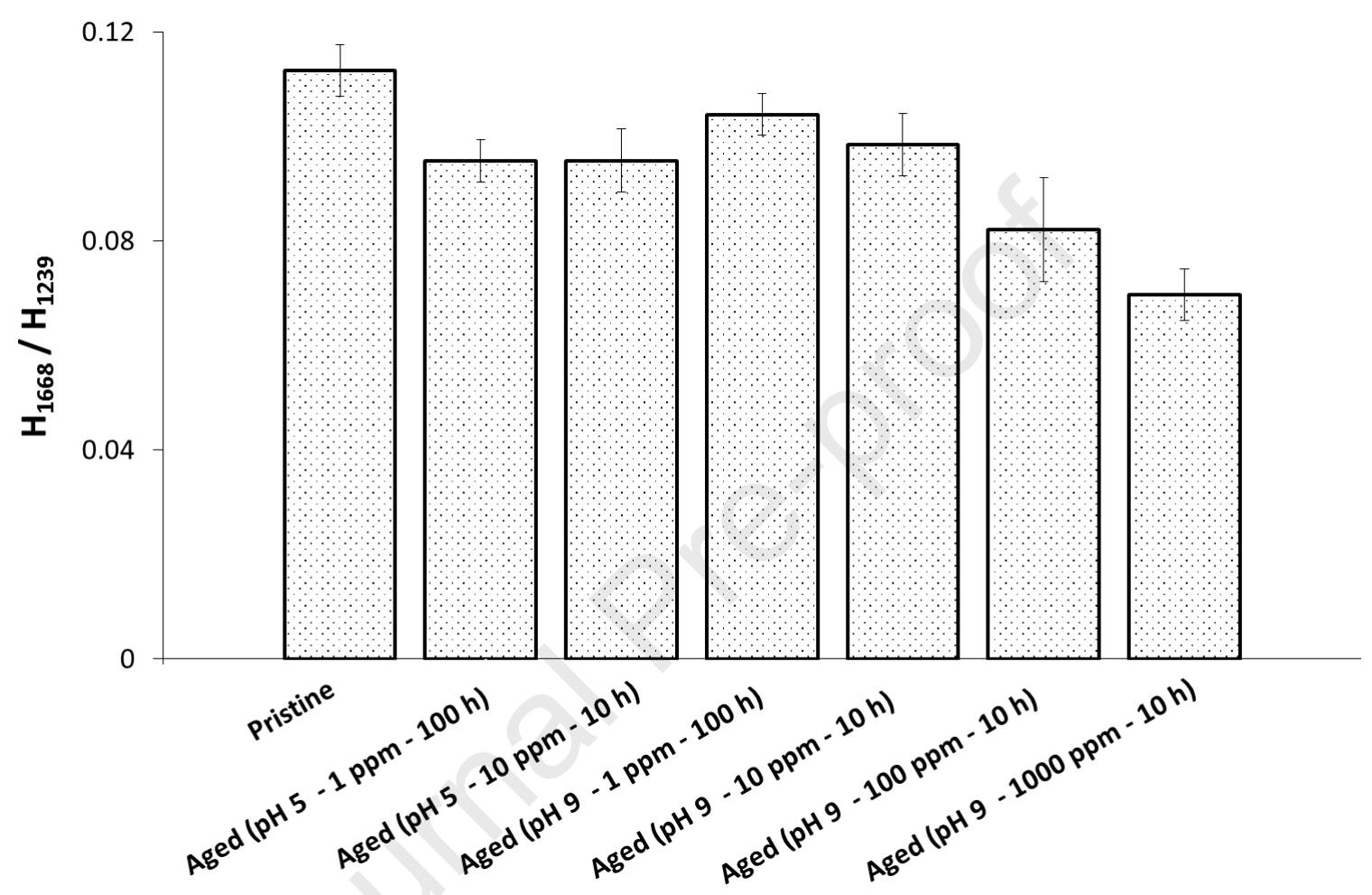

Figure 9. Ratio of band heights detected at $1668 \mathrm{~cm}^{-1}$ and $1239 \mathrm{~cm}^{-1}$ by FTIR-ATR spectroscopy for membrane supports before and after exposure to $\mathrm{NaOCl}$.

For higher free chlorine doses (1000 and 10000 ppm.h), both $J_{s}$ and $J_{w}$ increased for aged AQP membranes with respect to the pristine one (Fig. 7). As discussed in Section 3.1, under severe ageing conditions, chlorination of the secondary amide groups suppresses a substantial amount of HBs between the PA chains. That provides the PA chains with more degrees of freedom, which makes the active layer more permeable to both water molecules and ions. The disruption of the HB network within the active layer, the decrease of the membrane charge density (with respect to lower free chlorine doses; see Fig. 6) along with the even more reduced ICP within the support material (as a result of the greater PVP release from the 
membrane support as shown in Fig. 9) explain the results reported in Fig. 7 at high free chlorine doses.

Interestingly, exposure to sodium hypochlorite and the resulting substantial physicochemical changes in the surface properties of the AQP membranes (see Section 3.1) had little effect on their ability to reject pharmaceutical compounds contained in the feed solution, whatever the $\mathrm{pH}$ of the sodium hypochlorite solution used in ageing experiments (see Fig. 10). Indeed, the rejections of naproxen and diclofenac were as high as 97.6 and $98.4 \%$, respectively, with the pristine AQP membrane and they remained higher than $95.9 \%$ for the aged membranes, whatever the ageing conditions. These results indicate that the membrane active layer remained dense after ageing. The strong negative charge density of AQP membranes also contributed to the high rejection of diclofenac and naproxen as both of them were negatively charged at the $\mathrm{pH}$ of FO experiments $\left(p K_{a}=4.15\right.$, see Table 2$)$.

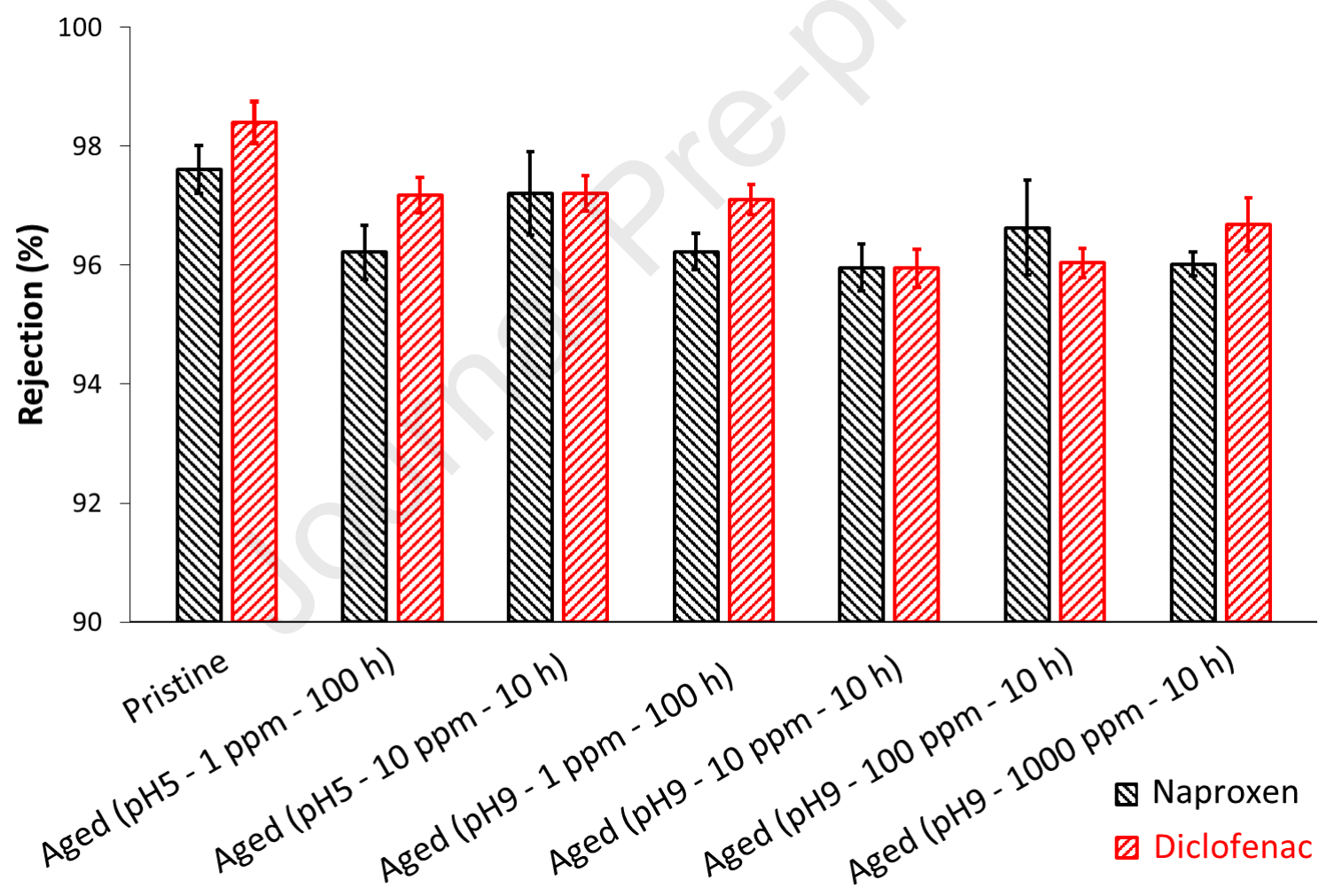

Figure 10. Rejection of naproxen and diclofenac by new and aged AQP membranes.

To conclude, although exposure to sodium hypochlorite was found to have a detrimental effect on the amount of draw-solute loss per unit of water passed $\left(J_{s} / J_{w}\right.$ rose from 0.4 g.L $\mathrm{L}^{-1}$ for the pristine membrane up to about $7 \mathrm{~g} . \mathrm{L}^{-1}$ for the highest free chlorine dose), the overall ability of AQP membranes to reject diclofenac and naproxen was maintained. Of course, a 
specific reverse solute flux as high as $7 \mathrm{~g} / \mathrm{L}$ would not be acceptable in a practical situation (in a continuous FO process, the increase in the retentate salinity would be negligible but the loss of draw solute would lead to additional operating cost). However, it is noteworthy that the doses of free chlorine used in this study were much higher (as usual in lab-scale ageing studies) than those to which a membrane would be exposed in a real application. Even the lowest doses considered in this work, i.e. $100 \mathrm{ppm} . \mathrm{h}$, are to be considered substantial. Indeed, in a practical case, the only possibility of contact between the membrane and free chlorine is an accidental contact with residual oxidizing agents in case of an incomplete dechlorination (it might occasionally occur in water and wastewater treatment).

The greater loss of the draw solution after ageing most likely came from the impact of sodium hypochlorite on the membrane support. The solution to limit the increase in the specific reverse solute flux after contact with large doses of free chlorine could be the use of a draw solute leading to a much lower reverse flux than $\mathrm{NaCl}$. In this regard, asymmetric salts such as e.g. $\mathrm{MgCl}_{2}$ might be used as the large hydrated radius of divalent cations substantially limit the reverse flux compared with $\mathrm{NaCl}$ (but asymmetric salts would enhance ICP due to lower diffusivity, which would negatively impact the water flux) [51]. Polyelectrolytes such as poly (acrylic acid sodium salt) or poly (aspartic acid sodium salt) might also be used as draw solutes as they have been shown to lead to water fluxes close to those reported with inorganic salts while exhibiting markedly lower reverse fluxes [52, 53].

\section{Conclusion}

Sodium hypochlorite resistance of FO biomimetic membranes with polymersomes incorporating Aquaporin $\mathrm{Z}$ proteins was investigated. Membranes were exposed to various free chlorine doses under acidic ( $\mathrm{pH} 5)$ and alkaline ( $\mathrm{pH}$ 9) conditions.

Exposure to sodium hypochlorite led to a significant modification of the membrane surface properties, partly due to the disruption of the hydrogen-bond network within the polyamidebased active layer of the biomimetic membranes. Membrane ageing did not impact the polymersome embedment in the polyamide active layer of the membranes.

Changes in the membrane surface properties were further correlated with the modifications of FO performance. Degradation caused by sodium hypochlorite increased the draw-solute loss per unit of water passed. The greater loss of the draw solution after ageing most likely came from the reduction of the internal concentration polarization due to the impact of sodium hypochlorite on the membrane support material. 
A limited impact of ageing was found on the rejection of two non-steroidal anti-inflammatory drugs (naproxen and diclofenac), which remained higher than $95.9 \%$ although the membranes were exposed to much higher doses of free chlorine than would be expected in a practical situation.

\section{Acknowledgements}

The Ministry of Higher Education and Scientific Research of Algeria and Campus France are gratefully acknowledged for providing W. Ghamri with a Profas B+ grant (960923G). Campus France is also acknowledged for financial support through PHC Proteus program (40023WM).

I. Petrinic and C. Hélix-Nielsen gratefully acknowledge support from the NepWat project supported by the NovoNordisk Foundation (grant NNF18OC0034918).

The authors express their thanks to G. Ildiko and R. Berta (University of Pannonia, Hungary) for the HPLC analyses, J. Hamon (Institut des Matériaux Jean Rouxel, Nantes) for XPS measurements, F. Gouttefangeas (ScanMAT, University of Rennes 1) for SEM images and R. Mallet (SCIAM microscopy platform, University of Angers) for AFM experiments.

\section{References}

[1] E. Drioli, A.I. Stankiewicz, F. Macedonio, Membrane engineering in process intensification-An overview, J. Membr. Sci. 380 (2011) 1-8. https://doi.org/10.1016/j.memsci.2011.06.043.

[2] T. Cath, A. Childress, M. Elimelech, Forward osmosis: Principles, applications, and recent developments, J. Membr. Sci. 281 (2006) 70-87. https://doi.org/10.1016/j.memsci.2006.05.048.

[3] C. Tang, Z. Wang, I. Petrinić, A.G. Fane, C. Hélix-Nielsen, Biomimetic aquaporin membranes coming of age, Desalination. 368 (2015) 89-105. https://doi.org/10.1016/j.desal.2015.04.026.

[4] Y.C. Kim, S.-J. Park, Experimental Study of a 4040 Spiral-Wound Forward-Osmosis Membrane Module, Environ. Sci. Technol. 45 (2011) 7737-7745. https://doi.org/10.1021/es202175m.

[5] A. D'Haese, P. Le-Clech, S. Van Nevel, K. Verbeken, E.R. Cornelissen, S.J. Khan, A.R.D. Verliefde, Trace organic solutes in closed-loop forward osmosis applications: Influence of membrane fouling and modeling of solute build-up, Water Res. 47 (2013) 5232-5244. https://doi.org/10.1016/j.watres.2013.06.006.

[6] V. Sant'Anna, L.D.F. Marczak, I.C. Tessaro, Membrane concentration of liquid foods by forward osmosis: Process and quality view, J. Food Eng. 111 (2012) 483-489. https://doi.org/10.1016/j.jfoodeng.2012.01.032.

[7] G.Q. Chen, S.L. Gras, S.E. Kentish, The application of forward osmosis to dairy processing, Sep. Purif. Technol. 246 (2020) 116900. https://doi.org/10.1016/j.seppur.2020.116900.

[8] A. Alturki, J. McDonald, S.J. Khan, F.I. Hai, W.E. Price, L.D. Nghiem, Performance of a novel osmotic membrane bioreactor (OMBR) system: Flux stability and removal of trace organics, Bioresour. Technol. 113 (2012) 201-206. https://doi.org/10.1016/j.biortech.2012.01.082. 
[9] J. Zhang, W.L.C. Loong, S. Chou, C. Tang, R. Wang, A.G. Fane, Membrane biofouling and scaling in forward osmosis membrane bioreactor, J. Membr. Sci. 403-404 (2012) 8-14. https://doi.org/10.1016/j.memsci.2012.01.032.

[10] F. Kong, H. Yang, Y. Wu, X. Wang, Y.F. Xie, Rejection of pharmaceuticals during forward osmosis and prediction by using the solution-diffusion model, J. Membr. Sci. 476 (2015) 410-420. https://doi.org/10.1016/j.memsci.2014.11.026.

[11] D. Jang, S. Jeong, A. Jang, S. Kang, Relating solute properties of contaminants of emerging concern and their rejection by forward osmosis membrane, Sci. Total Environ. 639 (2018) 673678. https://doi.org/10.1016/j.scitotenv.2018.05.078.

[12] H. Lee, S.-J. Im, J.H. Park, A. Jang, Removal and transport behavior of trace organic compounds and degradation byproducts in forward osmosis process: Effects of operation conditions and membrane properties, Chem. Eng. J. 375 (2019) 122030. https://doi.org/10.1016/j.cej.2019.122030.

[13] N.T. Hancock, P. Xu, D.M. Heil, C. Bellona, T.Y. Cath, Comprehensive Bench- and Pilot-Scale Investigation of Trace Organic Compounds Rejection by Forward Osmosis, Environ. Sci. Technol. 45 (2011) 8483-8490. https://doi.org/10.1021/es201654k.

[14] H.T. Madsen, N. Bajraktari, C. Hélix-Nielsen, B. Van der Bruggen, E.G. Søgaard, Use of biomimetic forward osmosis membrane for trace organics removal, J. Membr. Sci. 476 (2015) 469-474. https://doi.org/10.1016/j.memsci.2014.11.055.

[15] J. Xu, P. Li, M. Jiao, B. Shan, C. Gao, Effect of Molecular Configuration of Additives on the Membrane Structure and Water Transport Performance for Forward Osmosis, ACS Sustain. Chem. Eng. 4 (2016) 4433-4441. https://doi.org/10.1021/acssuschemeng.6b01039.

[16] T.P.N. Nguyen, B.-M. Jun, Y.-N. Kwon, The chlorination mechanism of integrally asymmetric cellulose triacetate (CTA)-based and thin film composite polyamide-based forward osmosis membrane, J. Membr. Sci. 523 (2017) 111-121. https://doi.org/10.1016/j.memsci.2016.09.020.

[17] L. Xia, M.F. Andersen, C. Hélix-Nielsen, J.R. McCutcheon, Novel Commercial Aquaporin Flat-Sheet Membrane for Forward Osmosis, Ind. Eng. Chem. Res. 56 (2017) 11919-11925. https://doi.org/10.1021/acs.iecr.7b02368.

[18] Y. Chun, L. Qing, G. Sun, M.R. Bilad, A.G. Fane, T.H. Chong, Prototype aquaporin-based forward osmosis membrane: Filtration properties and fouling resistance, Desalination. 445 (2018) 75-84. https://doi.org/10.1016/j.desal.2018.07.030.

[19] M. Kumar, M. Grzelakowski, J. Zilles, M. Clark, W. Meier, Highly permeable polymeric membranes based on the incorporation of the functional water channel protein Aquaporin Z, Proc. Natl. Acad. Sci. 104 (2007) 20719-20724. https://doi.org/10.1073/pnas.0708762104.

[20] Y. Zhao, C. Qiu, X. Li, A. Vararattanavech, W. Shen, J. Torres, C. Hélix-Nielsen, R. Wang, X. Hu, A.G. Fane, C.Y. Tang, Synthesis of robust and high-performance aquaporin-based biomimetic membranes by interfacial polymerization-membrane preparation and RO performance characterization, J. Membr. Sci. 423-424 (2012) 422-428. https://doi.org/10.1016/j.memsci.2012.08.039.

[21]Z. Li, R. Valladares Linares, S. Bucs, L. Fortunato, C. Hélix-Nielsen, J.S. Vrouwenvelder, N. Ghaffour, T. Leiknes, G. Amy, Aquaporin based biomimetic membrane in forward osmosis: Chemical cleaning resistance and practical operation, Desalination. 420 (2017) 208-215. https://doi.org/10.1016/j.desal.2017.07.015.

[22] C.Y. Tang, Y. Zhao, R. Wang, C. Hélix-Nielsen, A.G. Fane, Desalination by biomimetic aquaporin membranes: Review of status and prospects, Desalination. 308 (2013) 34-40. https://doi.org/10.1016/j.desal.2012.07.007.

[23] M. Xie, W. Luo, H. Guo, L.D. Nghiem, C.Y. Tang, S.R. Gray, Trace organic contaminant rejection by aquaporin forward osmosis membrane: Transport mechanisms and membrane stability, Water Res. 132 (2018) 90-98. https://doi.org/10.1016/j.watres.2017.12.072.

[24] R. Górecki, D.M. Reurink, M.M. Khan, V. Sanahuja-Embuena, K. Trzaskuś, C. Hélix-Nielsen, Improved reverse osmosis thin film composite biomimetic membranes by incorporation of 
polymersomes, J. Membr. Sci. 593 (2020) 117392.

https://doi.org/10.1016/j.memsci.2019.117392.

[25] B. Valverde-Pérez, M.L. Pape, A.F. Kjeldgaard, A.A. Zachariae, C. Schneider, C. Hélix-Nielsen, A. Zarebska, B.F. Smets, Dewatering methanotrophic enrichments intended for single cell protein production using biomimetic aquaporin forward osmosis membranes, Sep. Purif. Technol. 235 (2020) 116133. https://doi.org/10.1016/j.seppur.2019.116133.

[26] A. Szymczyk, C. Labbez, P. Fievet, B. Aoubiza, C. Simon, Streaming potential through multilayer membranes, AIChE J. 47 (2001) 2349-2358. https://doi.org/10.1002/aic.690471019.

[27] P. Fievet, M. Sbaï, A. Szymczyk, Analysis of the pressure-induced potential arising across selective multilayer membranes, J. Membr. Sci. 264 (2005) 1-12. https://doi.org/10.1016/j.memsci.2005.04.011.

[28] P. Fievet, M. Sbaï, A. Szymczyk, C. Magnenet, C. Labbez, A. Vidonne, A New Tangential Streaming Potential Setup for the Electrokinetic Characterization of Tubular Membranes, Sep. Sci. Technol. 39 (2004) 2931-2949. https://doi.org/10.1081/SS-200028652.

[29] A. Szymczyk, Y.I. Dirir, M. Picot, I. Nicolas, F. Barrière, Advanced electrokinetic characterization of composite porous membranes, J. Membr. Sci. 429 (2013) 44-51. https://doi.org/10.1016/j.memsci.2012.11.076.

[30] C.J. Van Oss, M.K. Chaudhury, R.J. Good, Interfacial Lifshitz-van der Waals and polar interactions in macroscopic systems, Chem. Rev. 88 (1988) 927-941. https://doi.org/10.1021/cr00088a006.

[31] K.C. Kedwell, M.L. Christensen, C.A. Quist-Jensen, M.K. Jørgensen, Effect of reverse sodium flux and $\mathrm{pH}$ on ammoniacal nitrogen transport through biomimetic membranes, Sep. Purif. Technol. 217 (2019) 40-47. https://doi.org/10.1016/j.seppur.2019.02.001.

[32] E. Idil Mouhoumed, A. Szymczyk, A. Schäfer, L. Paugam, Y.H. La, Physico-chemical characterization of polyamide NF/RO membranes: Insight from streaming current measurements, J. Membr. Sci. 461 (2014) 130-138. https://doi.org/10.1016/j.memsci.2014.03.025.

[33] V. Freger, S. Srebnik, Mathematical model of charge and density distributions in interfacial polymerization of thin films, J. Appl. Polym. Sci. 88 (2003) 1162-1169. https://doi.org/10.1002/app.11716.

[34] H. Zhu, A. Szymczyk, B. Balannec, On the salt rejection properties of nanofiltration polyamide membranes formed by interfacial polymerization, J. Membr. Sci. 379 (2011) 215-223. https://doi.org/10.1016/j.memsci.2011.05.062.

[35] Y. Kwon, J. Leckie, Hypochlorite degradation of crosslinked polyamide membranesll. Changes in hydrogen bonding behavior and performance, J. Membr. Sci. 282 (2006) 456-464. https://doi.org/10.1016/j.memsci.2006.06.004.

[36] J.M. Gohil, A.K. Suresh, Chlorine attack on reverse osmosis membranes: Mechanisms and mitigation strategies, J. Membr. Sci. 541 (2017) 108-126. https://doi.org/10.1016/j.memsci.2017.06.092.

[37] R. Verbeke, V. Gómez, I.F.J. Vankelecom, Chlorine-resistance of reverse osmosis (RO) polyamide membranes, Prog. Polym. Sci. 72 (2017) 1-15. https://doi.org/10.1016/j.progpolymsci.2017.05.003.

[38] A. Subramani, E.M.V. Hoek, Direct observation of initial microbial deposition onto reverse osmosis and nanofiltration membranes, J. Membr. Sci. 319 (2008) 111-125. https://doi.org/10.1016/j.memsci.2008.03.025.

[39] I.M. Wienk, E.E.B. Meuleman, Z. Borneman, T. van den Boomgaard, C.A. Smolders, Chemical treatment of membranes of a polymer blend: Mechanism of the reaction of hypochlorite with poly(vinyl pyrrolidone), J. Polym. Sci. Part Polym. Chem. 33 (1995) 49-54. https://doi.org/10.1002/pola.1995.080330105.

[40] Y. Hanafi, A. Szymczyk, M. Rabiller-Baudry, K. Baddari, Degradation of Poly(Ether Sulfone)/Polyvinylpyrrolidone Membranes by Sodium Hypochlorite: Insight from Advanced Electrokinetic Characterizations, Environ. Sci. Technol. 48 (2014) 13419-13426. https://doi.org/10.1021/es5027882. 
[41] T. Kawaguchi, H. Tamura, Chlorine-resistant membrane for reverse osmosis. I. Correlation between chemical structures and chlorine resistance of polyamides, J. Appl. Polym. Sci. 29 (1984) 3359-3367. https://doi.org/10.1002/app.1984.070291113.

[42] N.P. Soice, A.C. Maladono, D.Y. Takigawa, A.D. Norman, W.B. Krantz, A.R. Greenberg, Oxidative degradation of polyamide reverse osmosis membranes: Studies of molecular model compounds and selected membranes, J. Appl. Polym. Sci. 90 (2003) 1173-1184. https://doi.org/10.1002/app.12774.

[43] R. Renou, A. Szymczyk, A. Ghoufi, Water confinement in nanoporous silica materials, J. Chem. Phys. 140 (2014) 044704. https://doi.org/10.1063/1.4862648.

[44] B. Pellegrin, R. Prulho, A. Rivaton, S. Thérias, J.-L. Gardette, E. Gaudichet-Maurin, C. Causserand, Multi-scale analysis of hypochlorite induced PES/PVP ultrafiltration membranes degradation, J. Membr. Sci. 447 (2013) 287-296. https://doi.org/10.1016/j.memsci.2013.07.026.

[45] M. Rabiller-Baudry, A. Bouzin, C. Hallery, J. Girard, C. Leperoux, Evidencing the chemical degradation of a hydrophilised PES ultrafiltration membrane despite protein fouling, Sep. Purif. Technol. 147 (2015) 62-81. https://doi.org/10.1016/j.seppur.2015.03.056.

[46] R. Prulho, S. Therias, A. Rivaton, J.-L. Gardette, Ageing of polyethersulfone/polyvinylpyrrolidone blends in contact with bleach water, Polym. Degrad. Stab. 98 (2013) 1164-1172. https://doi.org/10.1016/j.polymdegradstab.2013.03.011.

[47] Y. Hanafi, P. Loulergue, S. Ababou-Girard, C. Meriadec, M. Rabiller-Baudry, K. Baddari, A. Szymczyk, Electrokinetic analysis of PES/PVP membranes aged by sodium hypochlorite solutions at different pH, J. Membr. Sci. 501 (2016) 24-32. https://doi.org/10.1016/j.memsci.2015.11.041.

[48] Y. Kourde-Hanafi, P. Loulergue, A. Szymczyk, B. Van der Bruggen, M. Nachtnebel, M. RabillerBaudry, J.-L. Audic, P. Pölt, K. Baddari, Influence of PVP content on degradation of PES/PVP membranes: Insights from characterization of membranes with controlled composition, J. Membr. Sci. 533 (2017) 261-269. https://doi.org/10.1016/j.memsci.2017.03.050.

[49] B. Pellegrin, F. Mezzari, Y. Hanafi, A. Szymczyk, J.-C. Remigy, C. Causserand, Filtration performance and pore size distribution of hypochlorite aged PES/PVP ultrafiltration membranes, J. Membr. Sci. 474 (2015) 175-186. https://doi.org/10.1016/j.memsci.2014.09.028.

[50] Q. She, R. Wang, A.G. Fane, C.Y. Tang, Membrane fouling in osmotically driven membrane processes: A review, J. Membr. Sci. 499 (2016) 201-233. https://doi.org/10.1016/j.memsci.2015.10.040.

[51] D.J. Johnson, W.A. Suwaileh, A.W. Mohammed, N. Hilal, Osmotic's potential: an overview of draw solutes for forward osmosis, Desalination 434 (2018) 100-120. https://doi.org/10.1016/j.desal.2017.09.017.

[52] Q. Ge, J. Su, G.L. Amy, T.-S. Chung, Exploration of polyelectrolytes as draw solutes in forward osmosis processes, Water Res. 46 (2012) 1318-1326. https://doi.org/10.1016/j.watres.2011.12.043.

[53] G. Gwak, B. Jung, S. Han, S. Hong, Evaluation of poly (aspartic acid sodium salt) as a draw solute for forward osmosis, Water Res. 80 (2015) 294-305.

https://doi.org/10.1016/ j.watres.2015.04.041. 


\section{Highlights}

- Assessment of chorine resistance of biomimetic aquaporin FO membranes

- Chlorination strongly modified the HB network in the membrane active layer

- Non-monotonous variation of the water flux and increase of the reverse salt flux

- Reduced ICP due to ageing of the membrane support material

- Biomimetic FO membranes kept high rejection towards pharmaceutical compounds 


\section{Declaration of interests}

$\bigotimes$ The authors declare that they have no known competing financial interests or personal relationships that could have appeared to influence the work reported in this paper.

$\square$ The authors declare the following financial interests/personal relationships which may be considered as potential competing interests:

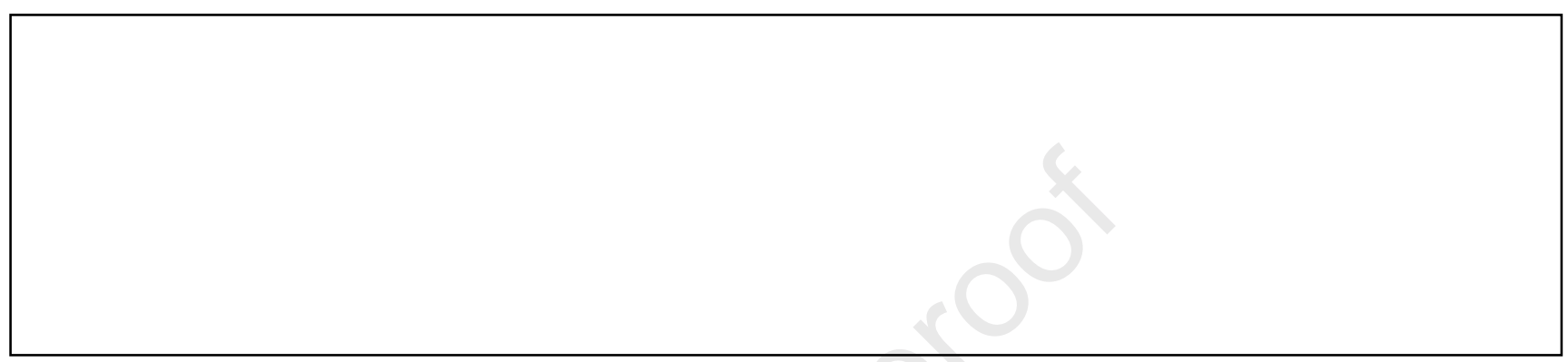

